\title{
PERJUANGAN PEREMPUAN SANTANA MASA KOLONIAL DALAM NOVEL GOGODA KA NU NGARORA KARYA M.A. SALMUN
}

Santana Women's Struggle of The Colonial Period

in The Novel "Gogoda ka nu Ngarora" By M.A. Salmun

\author{
Asep Yusup Hudayat \\ Fakultas Ilmu Budaya, Universitas Padjadjaran \\ yusuphudayat@gmail.com
}

Naskah diterima: 8 April 2021; direvisi: 11 Juni 2021 ; disetujui: 21 Juni 2021 doi: https://doi.org/10.26499/jentera.v10i1.3536

\begin{abstract}
Abstrak
Artikel ini mengungkap perjuangan perempuan santana (kelas menengah) pada masa kolonial yang direpresentasikan dalam novel Gogoda ka nu Ngarora karya M.A. Salmun. Perjuangan perempuan santana tidak saja melekat kepada upaya pembebasan diri dari banyak kungkungan patriarki tetapi juga ditunjukkan melalui cara perempuan santana menempatkan diri sebagai subjek yang "belajar" dari budaya kolonial. Budaya kolonial diterima perempuan santana untuk mengembangkan wawasan, juga sebagai sumber peniruan. Gogoda ka nu Ngarora 'Godaan bagi Kawula Muda' yang berkisah tentang kaum pribumi pada 1870-an hingga 1880-an merepresentasikan perjuangan perempuan santana dalam kungkungan feodalisme melalui penerimaan atas modernitas yang dibawa pihak kolonial. Cara-cara penerimaan perempuan santana yang dipicu kesadaran untuk menuntut berbagai hak dalam semangat demokrasi menjadi penting untuk dijejak berdasarkan perspektif poskolonial. Dengan demikian, masalah pokok yang akan dijawab dalam penelitian ini adalah bagaimana perempuan santana mengadopsi dan mengekspresikan kebudayaan kolonial dalam kepentingan perjuangan menuntut berbagai hak melalui pengungkapan praktik mimikri dan ambivalensi yang dilakukan secara dialektis. Hasil penelitian ini adalah perempuan santana ditempatkan dalam Gogoda ka nu Ngarora untuk menyangkal dan menggugat kesewenangan kaum ménak. Kaum ménak yang dilemahkan adalah bentuk pembelaan Salmun terhadap santana dan cacah. Semangat meruntuhkan penindasan kaum ménak dilakukan perempuan santana melalui mimikri yang mengarah kepada tindakan mengolok-olok kaum ménak sekaligus untuk menggangu otoritas utama, yaitu kolonial.
\end{abstract}

Kata kunci: perempuan, kelas menengah, mimikri, kolonial

\begin{abstract}
This article reveals the struggle of the santana (middle class) women during the colonial period as represented in the novel Gogoda ka nu Ngarora by M.A. Salmun. The struggle of the santana women was not only attached to the self-efforts of many patriarchal confines but also shown through the way the santana women position themselves as subjects who "learned" from colonial culture. The colonial culture that the santana women accepted to develop their knowledge was also a source of imitation. Gogoda ka nu Ngarora 'Temptation for Young People' which told about the indigenous people in the 1870s to 1880s represented the struggle of the santana women in the confines of feudalism through the acceptance of modernity brought by the colonial side. It was important to trace the way the santana women accepted that they raised awareness to demand various rights in a democracy from a postcolonial perspective. Thus, the main problem that will be answered in this research is how santana women adopt and express colonial culture in the interests of the struggle to demand various rights through the disclosure of dialectical mimicry and ambivalence practices. The result of this research is that santana women were placed in Gogoda ka nu Ngarara to deny and sue the arbitrariness of the menak. The weakened menak was a form of defense of Salmun towards santana and cacah. The spirit of destroying the menaks carried out by the Santana women through mimicry led to the act of making fun of the menaks as well as to disrupt the main authority, namely colonialism.
\end{abstract}

Keywords: women, middle class, mimicry, colonial 
How to Cite: Hudayat, Asep Yusup. (2021). Perjuangan Perempuan Santana Masa Kolonial dalam Novel Gogoda $\mathrm{Ka} \mathrm{Nu}$ Ngarora Karya M.A. Salmun. Jentera: Jurnal Kajian Sastra, 10(1), 1-16. Doi: https://doi.org/10.26499/jentera.v10i1.3536

\section{PENDAHULUAN}

Novel Gogoda ka nu Ngarora (GN) 'Godaan bagi Muda-Mudi’ karya M.A. Salmun yang terbit pertama kali tahun 1951 merupakan karya sambutan terhadap novel Sunda pertama Baruang ka nu Ngarora (BN) 'Racun bagi Muda-Mudi' karya D.K. Ardiwinata yang pertama terbit tahun 1914. Kedua novel tersebut diperlakukan dalam kritik yang berbeda. Rosidi (2002: 24) menilai $B N$ sebagai karya sastra bermutu, sedangkan GN ditempatkan sebagai sastra kitsch belaka. Rosidi (2002: 16) menyatakan bahwa sastra Sunda membutuhkan dasar kesadaran. Ia secara esensial menanyakan apakah para pengarang secara sadar telah menganggap sastra sebagai saksi hidup dari kehidupan manusia.

Meski $G N$ mendapat kritikan sebagai karya kitsch, tetapi bagi perspektif poskolonial, karya tersebut tetap berharga mengingat $G N$ secara dominan menyuarakan kelas menengah pribumi yang dengan lantang menggugat dan berjuang melawan kesewenangan kaum ménak dan kaum kolonial. Suara-suara kelas tersebut menjadi wacana penting terkait isu demokrasi yang dibawa peradaban Barat dan berpengaruh terhadap cara berpikir kaum pribumi tentang kelas. Pemberontakan kalangan santana (menengah) dan cacah (jelata) terhadap kaum ménak (ningrat) yang direpresentasikan Salmun dalam novel GN mengindikasikan adanya upaya penyeimbangan terhadap otoritas kaum ménak dan pihak kolonial. $G N$ dapat dianggap sebagai karya penyeimbang atas $B N$.

Keberpihakan pengarang terhadap kaum ménak tampak jelas di dalam BN. Sementara, di dalam GN, suara-suara kelas santana dihadirkan secara tegas dalam bentuk-bentuk penginterogasian terhadap tokoh-tokoh berstatus ménak. Narator pun secara dominan berperan dalam penunjukan dan keberpihakan terhadap kaum santana dan cacah atas kesewenangan kaum ménak dan kolonial. Namun demikian, penginterogasian serupa pun dilakukan terhadap golongan santana dan cacah. Kaum ménak, santana, cacah, ataupun kolonial pada akhirnya harus menanggung akibat buruk karena menjalankan mim pitu (maen, minum, madon, maling, mangani, madat, maehan 'berjudi, minum minuman keras, bermain perempuan, mencuri, boros, madat, dan membunuh').

GN memunculkan tokoh-tokoh yang berada dalam persinggungan ménak-cacah pada masa kolonial. Latar penceritaan GN adalah masa Prianger Stelsel dan setelahnya. Dalam hal ini, berbagai peristiwa yang mengangkat perspektif kolonialisme tidak ditunjukkan secara 
gamblang. Namun demikian, kompleksitas hubungan kolonialis-ménak-santana-cacah menjadi wacana penting bagi penunjukan praktik kolonialisme dalam atmosfir feodal dengan tokoh-tokoh Indo-Belanda yang dijadikan pusat penghambaan dan hasrat kaum pribumi.

$G N$ berusaha menetralisasi dominasi feodal dengan cara mengoptimalkan semangat demokrasi yang dibawa Nyi Rapiah sebagai tokoh perempuan dari kalangan santana. GN mengantarkan berbagai masalah yang dihadapi seluruh pihak secara pukul rata dalam batasbatas tertentu. Beberapa tokoh dalam $G N$ ditempatkan sebagai sosok yang terjerat dalam godaan hidup dalam perangkap mim pitu dan digiring ke dalam akibat yang harus diderita oleh pelakunya masing-masing. Salmun berusaha memanfaatkan spirit demokratis untuk menunjukkan keyakinannya menyangkut kerakyatan dan keadilan. Fenomena mimikri dan ambivalensi pun turut hadir menegaskan adanya benturan dan pertarungan antara budaya feodal dan budaya kolonial.

Fenomena mimikri dan ambivalensi dalam masa pemerintahan Hindia Belanda tidak saja ditunjukkan melalui cara pribumi melakukan berbagai penyesuaian terhadap budaya yang dibawa kaum kolonial, tetapi juga cara kaum kolonial datang ke Bumi Nusantara dengan upaya penyesuaian terhadap budaya pribumi. Di dalamnya sama-sama menunjukkan kelabilan dalam menerima atau menolak budaya baru, menjaga budaya warisan leluhur sekaligus beradaptasi dengan budaya baru, atau bahkan mengubah diri ke dalam budaya baru untuk maksud-maksud tertentu. Menjejak ambivalensi yang muncul dalam masyarakat Jawa dalam masa kolonialisasi abad ke-19, Arnout Henricus van der Meer (2014: 21) menunjukkan bahwa pemerintahan kolonial Belanda memiliki banyak proyek yang terkait dengan kontrol budaya. Dengan membenamkan diri dalam masyarakat Jawa, Belanda menemukan cara untuk melegitimasi otoritas mereka melalui adat istiadat setempat, sopan santun, dan semiotik. Belanda melegitimasi otoritas kolonial mereka di negara induk dengan mengacu pada hak penaklukan di Jawa abad ke-19. Mereka melakukan hal tersebut dengan mengacu pada feodalisme dan pandangan dunia yang menyertainya. Menurutnya (2014: 23), selama fase feodalisasi, pemerintah kolonial sebaliknya sangat bergantung pada aristokrasi Jawa dan memberdayakan feodal untuk tujuan eksploitasi yang lebih efektif.

Dalam konteks kolonialiasi Hindia Belanda abad ke-19 dan awal abad ke-20, hubungan kaum ménak ditunjukkan Herlina (1998: 111) sebagai elite birokrasi tradisional yang bersubordinasi kepada birokrasi kolonial yang menyebabkan adanya suatu hubungan khusus antara kaum ménak dengan orang-orang Belanda. Sebagai akibatnya, terjadi juga hubungan antara orang Belanda dengan ménak bawahan. Di samping itu, kaum ménak juga 
berhubungan dengan orang-orang Belanda yang bukan pejabat pemerintah, yaitu para penguasa perkebunan. Kontrolir merupakan pejabat Belanda paling bawah yang banyak berhubungan dengan pejabat pribumi hingga ke tingkat desa. Ia bertugas sebagai penghubung antara para pejabat Belanda dengan pejabat pribumi. Hal ini menyebabkan adanya hubungan yang cukup akrab antara kontrolir dengan kaum ménak.

Kecamuk peradaban kolonial yang melarut di dalam budaya feodal juga diungkap Murwani melalui De Stille Kracht karya Louis Couperus dan Bumi Manusia karya Pamoedya Ananta Toer. Murwani (2013: 278-280) menyebutkan manusia mimikri adalah manusia "berbahaya" bagi otoritas kolonial karena kemiripan dan perlawanan yang dimilikinya. Osilasi dari Barat-Timur, dari wacana dominan dan wacana tandingan yang berlangsung, mengakibatkan tindak mimikri terus menerus. Karena mimic man tetaplah dalam kondisi serupa tetapi tidak sama, mereka menolak dan menegosiasi identitas, menjadi pribadi yang tercerabut dari akarnya (unhomely) dan bergerak dalam bias ambivalensi: meremehkan Timur, tetapi mencintainya.

Penelitian Tinneke Hellwig penting untuk dihubungkan dengan wacana subaltern yang terdapat dalam GN. Tinneke Hellwig (2001: 175) dalam artikelnya "Asian Women in the Lives of Dutch Tea Planters: Two Narratives from West Java" membahas dua contoh hubungan antarras yang berbeda, yakni perempuan Asia memainkan peran penting dalam kehidupan para penanam teh di Jawa Barat. Objek kajiannya adalah novel berbahasa Belanda berjudul Heren van de Thee (1992) karya Hella Haasse dan novel Melayu berjudul Pemboenoehan Doorman (1925) karya Tio Ie Soei. Dari salah satu hasil penelitiannya, Tinneke menemukan bahwa terdapat wanita yang mampu melewati batas ras dan kelas sosial yang tidak dapat dilanggar oleh pria Asia dengan cara yang sama. Penelitian Tinneke Hellwig tersebut menawarkan cara pemberian makna atas narasi-narasi yang tidak dikatakan atau tidak ditampilkan. Tinneke mengubah paradigma dari perempuan sebagai subaltern ke perempuan yang mampu melewati batas ras dan kelas sosial melalui pernikahan, pergundikan, dan hubungan khusus lainnya tanpa adanya ikatan hukum. Fenomena tersebut muncul pula dari cara Salmun mengubah Nyi Rapiah sebagai bagian subalter yang pada akhirnya mampu menembus batas ras dan kelas sosial. Nyi Rapiah tidak saja mampu menembus batas ras, tetapi juga mampu menggugat dan mengintimidasi kaum ménak dan kaum kolonial melalui jerat prostitusi.

Karena semangat zaman yang hadir pada $G N$ dipengaruhi oleh realitas masa kolonial Hindia Belanda, penelitian Richard Drayton menjadi relevan untuk memberi perspektif terkait 
GN sebagai representasi hegemoni Eropa abad ke-19 hingga pertengahan abad ke-20 melalui hegemoni Belanda di Bumi Nusantara. Richard Drayton (2019: 346) dalam penelitiannya tentang hegemoni Eropa secara global dalam kurun waktu 1750-1950 menjelaskan bahwa ras, kelas, dan budaya adalah gagasan konkret tentang "putih" versus yang lain melalui pembelahan kelas sosial seputar pembagian kerja, properti, dan hak prerogatif sosial, pendidikan, selera estetika, tata krama, dan tindakan kolektif yang masuk melalui berbagai cara dan penanda. Drayton (2019: 344) menyebutkan bahwa momen hegemoni Eropa dari sekitar 1750 hingga 1950 berkorelasi dengan gagasan tentang "peradaban" dan "putih". Hipotesis Drayton adalah bahwa sejarah global yang mengelilingi pembangunan globalisasi imperial Eropa modern awal dan yang mencapai kematangan pada awal abad kesembilan belas memiliki tiga pengaruh kunci: pertama, hegemoni Eropa terjadi sekitar 1750 hingga 1950; kedua, integrasi dan hubungan eksternal terkait produksi dan peningkatan kepentingan kelompok mediasi-negosiator dengan kelas menengah yang mengambil perannya; ketiga, terkait proses standarisasi imajinasi sosial, tata krama, dan adat istiadat menuju keseragaman. Menurutnya, dunia yang terintegrasi hanya bisa dibuat masuk akal melalui budaya massa dengan bentuk-bentuk penyederhanaan, pengabaian kompleksitas, atau kinerja kesederhanaan.

Drayton (2019: 358) menyimpulkan bahwa kaum borjuis masuk dan keluar Eropa, muncul di celah-celah hubungan dominasi. Kaum tersebut adalah kelas sosial yang menengahi kehidupan ekonomi dan datang mencari inklusi politik selanjutnya merintis hegemoni. Dalam krisis panjang yang menyebar melintasi abad kesembilan belas dan kedua puluh, klaim mereka tentang peran dalam konteks global didasarkan pada gagasan tentang peran sentral dalam kehidupan kolektif serta perilaku dan habitus yang memberi mereka kapasitas khusus untuk memimpin ke arah yang dibayangkan.

Hegemoni Eropa tersebut tidak dapat dilepaskan dari wacana imperialisme yang berjalan beriringan dengan penjelasan tentang penaklukan dan penciptaan instrumeninstrumen dominasi. Untuk mendedah wacana imperialisme tersebut, kajian poskolonial mengambil peran penting dalam menjejak berbagai penanda di dalamnya, termasuk mengenai lanskap geografi yang penting dalam memetakan perjalanan dan penyebaran imperialisme. Said (2017: 277) menegaskan bahwa tugas penting telaah sastra dalam perspektif poskolonial adalah menjejak lanskap geografi, termasuk di dalamnya perihal geografi pengalaman pihak penjajah dan pihak terjajah yang direpresentasikan di dalam karya sastra. Dalam novel, wacana-wacana terkait geografi, lanskap, dan seting adalah hal yang utama. Tugas telaahnya 
adalah menemukan berbagai penanda geografi yang direpresentasikan di dalam karya sastra dan menjelaskan seting yang menghubungkan karya dengan pengalaman sejarah yang lebih luas menyangkut menjajah dan dijajah.

Wacana imperialisme, hegemoni, dominasi, budaya pribumi, budaya kolonial, perjuangan perempuan, semangat demokrasi, fenomena mimikri, dan ambivalensi adalah wacana-wacana penting yang terkandung dalam $G N$ karya Salmun tersebut. $G N$ menunjukkan wacana perjuangan perempuan santana atas dominasi feodal dan kolonial. Antusias $G N$ menunjukkan bagaimana Nyi Rapiah sebagai perempuan santana dengan penuh semangat mengadopsi dan mengekspresikan kebudayaan kolonial dalam kepentingan perjuangan menuntut hak-haknya di bawah dominasi kaum ménak dalam latar feodal dan kolonial. Antusiasme tersebut masih menyisakan ruang pembacaan terkait cara perempuan santana bermimikri dengan kehidupan kolonialnya dalam melakukan perjuangan. Dengan demikian, penelitian ini diarahkan kepada pengungkapan perjuangan perempuan santana dalam mengatasi pengaruh dominan budaya feodal dan kolonial. Pengaruh tersebut mengindikasikan adanya benturan-benturan yang tidak terhindarkan sehingga mimikri dan ambivalensi pun menjadi bagian yang relevan untuk dijejak fenomenanya.

\section{LANDASAN TEORI}

Terkait visibilitas mimikri dan ambivalensi dalam benturan tradisi pribumi dan kolonial, Bhabha (2004: 128) menyatakan bahwa visibilitas mimikri selalu diproduksi di situs larangan berupa bentuk wacana kolonial: wacana di persimpangan jalan, hal yang diketahui dan diperbolehkan, serta hal yang diketahui haruslah dirahasiakan; wacana rahasia yang diucapkan itu dianggap melanggar aturan. Dengan demikian, Bhabha menyatakan bahwa perbedaan representasi selalu juga merupakan masalah otoritas. Menurutnya (2004: 130), yang mengartikulasikan perbedaan interdictory, tepatnya "adegan lain" dari Eropa abad kesembilan belas, adalah keinginan berkesadaran historis yang otentik. Manusia kolonial yang tidak terartikulasikan adalah proses kebingungan klasifikasi yang telah digambarkan Bhabha sebagai metonimi dari rantai pengganti etika dan wacana. Hal ini mengakibatkan pecahnya wacana kolonial sehingga dua sikap terhadap realitas eksternal tetap ada; seseorang membutuhkan kenyataan menjadi pertimbangan, sementara yang lain menolaknya dan menggantikannya dengan sebuah produk keinginan yang berulang, mengartikulasikan kembali "realitas" sebagai mimikri. 
Bhabha (dalam Loomba, 2003: 299) menyebutkan bahwa ambivalensi bukan saja sebagai penanda trauma subjek kolonial, tetapi juga sebagai ciri dari cara kerja otoritas kolonial serta perlawanannya. Kehadiran kolonial selalu ambivalen, terpecah antara menampilkan dirinya yang asli dan otoritatif dengan artikulasinya yang menunjukkan pengulangan dan perbedaan. Kondisi tersebut dapat berimbas kepada kaum pribumi yang berada dalam dilema antara menerima sekaligus menolak pengaruh yang hadir dalam kehidupannya. Bhabha menyatakan bahwa mimikri (peniruan) budaya kolonial memiliki efek merongrong otoritas kolonial.

\section{METODE PENELITIAN}

Metode yang digunakan dalam penelitian ini adalah metode eksploratif. Metode ini digunakan untuk menjejak hubungan pengaruh kekuasaan kolonial dengan berbagai pandangan dan sikap kaum pribumi terhadap kaum elite pribumi dan kolonial, termasuk upaya peniruan di dalamnya. Hubungan yang dimaksud merupakan hal yang perlu dijejak untuk mengungkap bagaimana peniruan-peniruan atas kehidupan kolonial mengindikasikan adanya upaya perlawanan dalam ekspresi mengolok-olok pihak kolonial.

Perspektif kedua menyangkut pendekatan yang digunakan, yaitu poskolonial. Poskolonial digunakan sebagai pendekatan atas teks dengan menitikberatkan pengungkapan praktik-praktik kekuasaan yang dijalankan kaum kolonial terhadap kaum jajahannya. Pemikiran tersebut digunakan sebagai landasan penelitian ini yang target kajian berpusat pada penjejakan cara perempuan pribumi mengadopsi dan mengekspresikan kebudayaan kolonial dalam kepentingan perjuangan menuntut hak-hak di lingkungan sosial. Cara penjejakan yang dimaksud dihimpun ke dalam tanda dan target telaah. Pada tahap pertama, tanda dominasi dijejak melalui wacana (1) perempuan dan kelas sosial, (2) perempuan dan kolonial, dan (3) perempuan dan demokrasi. Pada fokus pertama, dijejak perjuangan perempuan dalam mengatasi dominasi ménak (kelas atas); pada fokus kedua, dijejak perjuangan perempuan dalam mengakses wilayah Indo-Belanda untuk mendapatkan pengetahuan dan berbagai pengalaman modernitas; dan pada fokus ketiga, dijejak perjuangan perempuan dalam menggunakan ilmu pengetahuan tentang demokrasi untuk merebut persamaan hak sosial.

Tahap kedua menyangkut praktik mimikri untuk menjejak (1) upaya penguasaan perempuan santana atas otoritas ménak melalui praktik mimikri sebagai olok-olok, intimidasi, penggugatan; (2) upaya perempuan santana mengakses kehidupan "Barat" dengan jalan 
penyesuaian nilai, hasrat, dan perilaku; dan (3) upaya meniru perjuangan wanita Barat dalam memperoleh hak-hak yang sama.

\section{PEMBAHASAN}

\section{Pribumi-Kolonial}

Ruang-ruang narasi yang direntangkan Salmun dalam $G N$ dari awal sampai akhir kisah menempatkan tokoh-tokoh secara problematis. Tokoh-tokoh orang Belanda (bukan Indo-Belanda) dan ménak luhung 'ningrat yang agung' di dalam $G N$ tidak muncul secara dominan.

GN telah menunjukkan dengan cukup problematis kehadiran tokoh-tokoh IndoBelanda di dalam lingkungan kaum pribumi. Menyangkut hal ini, Salmun telah mengawali pandangannya, melalui narator, dengan menempatkan tokoh-tokoh Indo-Belanda sebagai tokoh-tokoh yang ditonjolkan dalam hubungannya dengan kaum pribumi. Ia menempatkan sebagian tokoh Belanda, yang selanjutnya diperjelas pada bagian lain, sebagai orang IndoBelanda. Tentunya, pada sepanjang momen pembacaan, pada akhirnya, hal tersebut mampu membuka celah-celah teks untuk ditafsir secara dialektis. Setidaknya, hal itu tampak pada peristiwa-peristiwa yang memunculkan pandangan narator menyangkut kesenangan kaum pribumi memasuki kehidupan kaum kolonial Belanda.

Salmun menempatkan wanita santana pribumi semakin dekat dengan kaum IndoBelanda; begitu juga wanita cacah (diwakili tokoh Nyi Dampi sebagai makelar prostitusi) mengambil bagian dalam meluluskan kepentingan-kepentingan perempuan santana. Hal tersebut dipertimbangkannya untuk membawa kaum pribumi kepada kemampuan mengatasi kendala hubungan yang berpangkal pada perbedaan kelas sosial. Narator menunjukkan perubahan Nyi Rapiah menjadi percaya diri dengan sikap-sikapnya yang berani sebagai akibat dari orang Indo-Belanda yang dekat dengannya.

Citra orang Belanda dan interaksinya dengan kaum pribumi dapat dilihat melalui salah satu pandangan narator terhadap Luih, tokoh Indo-Belanda. Narator menyebutkan bahwa Luih bisa semena-mena karena ia seorang Belanda yang kaya raya, bisa dengan leluasa masuk ke rumah para ménak. Narator pun menilai betapa kaum pribumi selalu menganggap orang Belanda itu berada dalam taraf yang lebih tinggi dari kaum pribumi. Pada masa itu, pribumi akan merasa naik harkatnya ketika mendapat teman berkebangsaan Belanda, meski sebagai seorang mandor atau kepala wesel kereta api (Salmun, 1966: 87). 
Pendapat Bezemer (dalam Gouda, 2007: 303) menjadi relevan untuk menempatkan kalangan peranakan dalam perspektif tertentu. Menurutnya, pada tahun akhir kekuasaan kolonial Belanda, masyarakat berdarah campuran multiwarna di Hindia mendapatkan makna baru. Kepercayaan yang buta pada "kekulitputihan" masyarakat Eropa yang universal, meskipun sejumlah anggotanya berdarah campuran, kehilangan sebagian kekuatan imajinatif. Lebih jelas daripada masa lalu, kaum Indo digambarkan sebagai pihak yang menguasai ruang bayang-bayang di antara putih dan cokelat, di antara majikan dan bawahan. Mereka mengembara hilir-mudik di antara kaum pribumi dan masyarakat Eropa. Mereka merupakan bagian populasi yang tidak bahagia, tidak puas, dan berbahaya.

Penilaian tersebut dapat direkonstruksi ke dalam kepentingan menghimpun perspektif secara lebih luas. Hal yang paling relevan dengan pengkonstruksian yang dimaksud, untuk menggunakan fakta realitas ke dalam pembacaan $G N$ menyangkut orang Indo-Belanda, dapat dilihat melalui cara $G N$ menghimpun dan mengatasi celah peristiwa yang dialami seorang Indo-Belanda bernama Hatebessy yang memiliki kulit sawo matang layaknya kulit milik kaum pribumi. Pada akhirnya, ia harus mengakui bahwa tidak ada kemurnian ras Eropa dalam dirinya sehingga ia pun dalam satu kondisi merasa malu dengan keadaan dirinya (Salmun, 1966: 182).

Kondisi yang dihadapi Hatebessy tersebut akan mengaktivasi pemahaman tentang citra tubuh dan warna kulit. Hal tersebut akan pula kembali menempatkan kaum Indo-Belanda dalam hubungan hierarkis: Belanda, Indo-Belanda, Pribumi. Perasaan malu yang ditunjukkan Hatebessy bersinggungan dengan kondisi gamang antara kepongahan sebagai Indo-Belanda dengan perasaan tertekan karena harus menerima bahwa dalam tubuhnya mengalir pula darah pribumi. Peristiwa tersebut mengonfirmasi nilai-nilai di dalamnya. Pemahaman citra kelas ditunjukkan melalui narator dan para tokoh di dalamnya. Familiaritas kelas ditunjukkan melalui tiga perspektif, yaitu citra kelas melalui permahaman ménak terhadap santana dan cacah; santana dan cacah terhadap ménak dan kaum kolonial; dan kaum kolonial terhadap pribumi. Perebutan narasi dominan pun terjadi satu dengan lainnya. Mengacu pada wacana dominasi, perjuangan perempuan santana berhasil menunjukkan dominasi terhadap ménak. Perempuan santana pun berhasil mengakses wilayah Indo-Belanda untuk mendapatkan pengetahuan dan berbagai pengalaman modernitas yang pada akhirnya digunakan sebagai alat mendominasi pihak ménak. Sehubungan dengan semangat demokrasi, perempuan santana dalam menggunakan pengalaman demokratisnya berhasil merebut persamaan hak sosial, bahkan beralih ke pendominasian terhadap kalangan ménak. 


\section{Perempuan dan Mimikri dalam Wacana Kolonial}

Novel GN merepresentasikan kaum santana yang menjadi pusat wacana dalam hubungannya dengan berbagai praktik kekuasaan feodal. Kaum santana pun berada di tengahtengah masyarakat jelata sekaligus memiliki kekuatan besar untuk melakukan penyeimbangan atas kaum ménak. Realitas yang diangkat dalam GN menempatkan novel ini sebagai novel ironi. Hal ini didasarkan pada upaya Salmun dalam mengatasi kesenjangan ménak-cacah, dengan cara melakukan sejumlah interogasi dan intimidasi melalui narator yang ditempatkannya secara dominan sebagai pihak yang menempati perspektif kaum santana. Kaum santana digunakan Salmun sebagai pihak yang berjuang dengan berbagai cara untuk mengatasi kesewenangan kaum ménak.

Salmun merasakan bahwa kekuatan ménak hanya dapat dilemahkan dengan meningkatkan kekuatan kaum santana dan cacah di hadapan kaum ménak. Banyak peristiwa yang ditunjukkan Salmun untuk mengondisikan kaum santana dan cacah dengan ujaranujaran togmol 'ujaran langsung ke pokok masalah tanpa ditahan'.

Bagi Salmun, pengetahuan yang melekat pada tokoh-tokoh tertentu, terutama Nyi Rapiah, digunakan sebagai jalan untuk memandang, secara spesifik, hal-hal menyangkut kelas sosial. Bahkan, melalui pengetahuan, tokoh-tokoh dibangkitkan dari keterpurukan kelas. Berikut ini pandangan narator $G N$ terhadap Nyi Rapiah sehubungan dengan pengetahuan yang dimilikinya dan pergaulan luasnya.

Bubuhan Nji Rapiah téh urang dajeuh, loba deudeuleuan-dédéngéan djeung sanadjan enja gé awéwé ropoh pager, ipis bendungan, da ari haténa mah tjaang, pikirna njaring boga bakat tjalakan. Ditambah sanggeus sering pulang anting ka Nji Dampi, tjampur djeung "kakasihna" nonoman balageur, palinter djeung réa nu boga bakat demokratis - maké ukuran taun 1875! -kusial baé rasa-pangaribawana hudang awas atra kana susunan masarakat. Bet réa kateuadilan! Naha bet masarakat kudu njieun golongan djelema diumpak-umpak, dikelas-kelas? Naha bet maké aja golongan ménak, aja golongan somah? ...Lamun djaman harita Nji Rapiah geus ngadéngé katjapangan "Keadilan Sosial", moal boa mepek balad ngabangkit hak-hak adiling-masyarakat! (Salmun, 1966: 69-70).

Karena Nyi Rapiah itu orang kota, ia menjadi banyak tahu; meskipun ia perempuan yang mudah rapuh, mudah terpengaruh, tetapi hatinya terang, pikirannya terjaga dan ia punya bakat pintar. Ditambah lagi setelah sering menemui ke Nyi Dampi, bergaul dengan "kekasihnya" para pemuda kaya raya, pandai dan banyak yang memiliki bakat demokratis- untuk ukuran tahun 1875 ! - muncullah rasa peduli dan jeli kepada tatanan masyarakat. Ternyata banyak ketidakadilan! Jika saat itu Nyi Rapiah sudah mendengar pernyataan "keadilan sosial", kemungkinan ia akan bergabung dengan rekan-rekannya untuk menuntut hak-hak keadilan masyarakat!

Tentu saja, pertimbangan Salmun menciptakan sosok baru Nyi Rapiah, dengan keterbukaan pikiran seperti itu, dimaksudkan untuk menjadikan Nyi Rapiah leluasa memasuki batas-batas kelas; tidak terkungkung lagi seperti sosok Nyi Rapiah yang digambarkan dalam $B N$. Sebagai pusat narasi, Nyi Rapiah diberi kemampuan untuk menunjukkan pandangan dan 
sikap atas kelas menak. Ia pun terhubung ke kehidupan pemuda-pemuda Indo-Belanda. Dari merekalah Nyi Rapiah mengalami kemajuan pemikiran. Adapun kemampuan menjangkau lingkungan kelas bawah menjadikan ia semakin mampu menunjukkan otoritas. Meskipun demikian, pada akhirnya, Salmun harus kembali terperangkap ke dalam pemahaman stereotipenya. Energi kebangkitan masyarakat menengah dan cacah, akhirnya, dilenyapkan seiring dengan ditempatkan Nyi Rapiah sebagai bagian yang harus menanggung akibat dari perbuatan hinanya sebagai pelacur.

Anggapan bahwa keputusan-keputusan yang diambil Nyi Rapiah dalam menunjukkan perlawanannya, pada akhirnya tidak lagi dimaklumi ketika berhadapan dengan nilai-nilai dasar ideal yang dipercayai Salmun. Satu-satunya tanggapan yang layak diterima pembaca pada situasi itu adalah menghindarkan diri dari pemahaman bahwa situasi tersebut sudah tidak bisa diharapkan lagi dalam menempatkan kepentingan Nyi Rapiah dengan kepentingannya sendiri yang bermaksud menggugurkan norma-norma kelas sosial yang ditentangnya.

Kekuatan yang diberikan Salmun kepada pembaca untuk dapat mengidentifikasi tokoh-tokoh di dalam $G N$, secara konsisten, ditunjukkan melalui fase-fase penceritaan yang mempertimbangkan berbagai tendensi pada setiap pergerakan cerita. Dalam $G N$, kaum ménak berada dalam perguncangan akibat berbagai sikap dan tindakan destruktif kaum santana dan cacah.

Salmun meletakkan semangat demokratis melalui pihak-pihak yang dianggapnya paling relevan untuk berhadapan dengan kaum feodal. Melalui pembagian fungsi di dalamnya, dapat dipahami kebenaran di balik ilusi yang ditampilkan tokoh-tokoh di dalamnya. Penyembunyian kebenaran di dalam teks $G N$ adalah sebagai hal yang memberikan berbagai efek tidak langsung bagi pembaca. Di sisi lain, para pembaca diarahkan untuk berada pada posisi tidak menyukai tokoh-tokoh kelas ménak yang dicitrakan sebagai tokoh yang tidak terjamah oleh kehinaan.

Kebaikan dan keburukan dalam pembicaraan kelas sosial sebagian besar diutarakan Salmun secara gamblang, terutama suara-suara yang mewakili kaum santana dan cacah. Dalam GN, Salmun cenderung melakukan karakterisasi kualitas tindakan dan pengalaman tertentu, yang dialami tokoh-tokoh di dalamnya, dengan melakukan identifikasi secara lugas. Kaum ménak atau kaum cacah adalah sebuah wilayah tempat sang penguasa atau sang tertindas sama-sama menumpahkan "sisi gelap dan cacat" yang sama-sama dimiliki. Namun, yang dijadikan pusat kekuatan baru adalah kaum santana, diwakili oleh Nyi Rapiah, yang terus bergerak meluluskan maksud perlawanannya atas kaum ménak dengan perjuangannya 
menembus wilayah kolonial dan kaum ménak pribumi dengan memanfaatkan pengetahuan tentang demokrasi dan perjuangan perempuan yang telah lebih dahulu bergerak di belahan Eropa.

Ketidaktoleranan Salmun atas kelas-kelas ménak, santana, dan cacah, dalam hal kesetiaan terhadap norma-norma ideal, menempatkan $G N$ sebagai bentuk aktualisasi Salmun yang meyakini bahwa kehancuran akan menimpa siapa pun jika mereka menjalankan mim pitu. GN yang menunjukkan pertentangan terhadap kaum ménak berkonsekuensi terhadap terbukanya rasa suka cita pembaca yang berada dalam perspektif norma-norma kerakyatan atas perjuangan kaum santana atau cacah dan atas dilumpuhkannya potensi kaum ménak dalam pencapaian berbagai praktik kekuasaan. Hal ini bersumber pada kondisi yang ditonjolkan Salmun pada setiap peristiwa melalui pelemahan intimidasi kaum ménak dan semangat perlawanan kaum santana terhadap ménak.

Rasa benci santana atau cacah terhadap ménak, dengan cara tertentu, merupakan cara lain Salmun dalam merepresentasikan kesukacitaan kaum santana atau cacah dalam kondisi ketidakberdayaan kaum ménak. Kaum santana atau cacah berpikir bahwa ménak terlalu sewenang-wenang. Yang sebenarnya ditunjukkan atau dipertaruhkan Salmun pada momen ini adalah, baik ménak, santana, maupun cacah, masing-masing mengalami rasa suka cita dengan cara yang berbeda-beda. Tiap-tiap kelas diberi rasa suka cita yang kemudian direnggut kembali oleh Salmun ke dalam kondisi menyedihkan. Tidak ada sikap toleran dari kaum santana atau cacah terhadap kaum ménak. Hal ini menempatkan kembali $G N$ dalam perspektif yang beralih-alih. Berdasarkan kondisi yang ditunjukkan dalam $G N$, jika dilihat dari perspektif norma kaum ménak, tampak adanya ketertekanan sepanjang cerita yang mengedepankan situasi otoritas kaum santana atau cacah terhadap kaum ménak. Jika perspektif dialihkan kepada kaum santana atau cacah yang ditempatkan Salmun sebagai subjek otoriter, terdapat kondisi penguasaan yang sepadan dengan tokoh-tokoh di dalamnya, terutama tokoh utama.

Narator menggerakkan tokoh-tokoh perempuan pada hampir seluruh teks naratifnya secara leluasa, sedikitnya menunjukkan bahwa narator mampu memetakan verbalisasinya ke dalam penguasaan maskulinitas melalui dominasi Nyi Rapiah sebagai perempuan santana. Ketidaktakutan mengekspresikan sifat feminin pada tokoh Aom Usman yang digunakan Salmun, bukan untuk mendukung pelulusan sehingga Nyi Rapiah tidak tertarik lagi kepada Aom yang ménak, melainkan untuk mendorong pergantian otoritas Aom Usman yang segera digantikan oleh otoritas baru dari pihak perempuan yang diwakili Nyi Rapiah. 
Verbalisasi "kasar" Salmun merepresentasi dua dimensi yang tidak menyenangkan tentang para ménak dan kaum cacah. Dua dimensi ini adalah unsur yang paling tegas dan mendasar pada $G N$ : kebencian atas kesewenangan kaum ménak kepada cacah dan kegusaran kepada kaum santana atau cacah yang sama-sama berbuat salah, seperti yang dilakukan kaum ménak, tetapi dengan cara yang berbeda.

Meskipun $G N$ berbicara tentang perjuangan Nyi Rapiah dengan caranya sendiri dalam bermimikri, pengamatan bisa diperluas terhadap Aom Usman atau Ujang Kusen, bahkan Salmun. Verbalisasi demokrasi dalam masyarakat feodal merupakan aspek ancaman paling relevan bagi kaum feodal yang biasa ingin meluluskan kepentingan kekuasaannya tanpa hambatan. Dengan melakukan proyeksi cinta antara Nyi Rapiah dan Aom Usman, kemudian disenjangkan kembali, mengakibatkan daya tolak $G N$ yang tinggi terhadap feodal.

Dalam $G N$, Nyi Rapiah digerakkan ke dalam semangat mencari kebebasan dari kungkungan Aom Usman sambil menyatakan sikap bahwa keadilan perlu ditegakkan dan persamaan derajat perlu diperjuangkan. Namun, pada akhirnya, pengarang harus pula menggiring Nyi Rapiah ke dalam kondisi akhir yang mengenaskan sebagai balasan atas perbuatan yang dianggap telah mencelakakan mantan suaminya, Ujang Kusen. Nyi Rapiah dirawat di rumah sakit karena menderita penyakit menular sebagai akibat kehidupan yang dia jalani sebagai pelacur. Demikian pula dengan Aom Usman yang telah mengganggu rumah tangga Ujang Kusen, akhirnya menjadi tidak berdaya di hadapan Nyi Rapiah yang semakin hari semakin berani menunjukkan sikapnya. Akhirnya, Aom Usman pun dihadapkan kepada hukuman berat dan dibuang ke penjara Surabaya atas kasus korupsi dan pembunuhan terhadap orang Belanda. Nyi Dampi dan Si Abdullah yang mewakili golongan jelata, yang menghamba kepada kepentingan ménak, harus meregang nyawanya akibat terbakar api dan meminum racun.

Nyi Rapiah sebagai tokoh sentral dalam GN menyerah pada "selera" pemberontakannya sendiri terhadap suaminya yang ménak dan terhadap kaum ménak lainnya. Ia tenggelam semakin dalam pada suasana yang tidak mempertimbangkan moral lagi meskipun sebenarnya moral sosial yang diperjuangkannya. Salmun menempatkan Nyi Rapiah sampai pada titik bahwa Nyi Rapiah tidak dapat kembali lagi. Ia terlepas dari kemungkinan diberikannya penyelamatan sosial. Namun demikian, tetap ada penyelamatan sosial yang diterima Nyi Rapiah. Sakit parah yang dideritanya mampu membuat Ujang Kusen (mantan Suami Nyi Rapiah) memaafkan kesalahan-kesalahan yang telah diperbuat Nyi Rapiah terhadap Ujang Kusen. 
$G N$ telah mengimplikasikan wilayah-wilayah pertemuan menyangkut representasi realitas. Melalui GN, dapat diketahui bahwa Salmun melihat: (1) hal yang direpresentasikan dalam kehidupan kolonial dan budaya feodal; (2) hal yang ditiadakan/disembunyikan dalam realitas menyangkut dominasi kelas dan hubungannya dengan otoritas kolonial; dan (3) hal yang seharusnya dimunculkan dalam $G N$ sebagai wacana penyeimbang atas $B N$. Hal pertama menyangkut kehidupan ménak dan cacah dalam persinggungan antara keduanya. Hal ini berhubungan dengan masalah substansial kelas sosial yang mengonfirmasi nilai-nilai kelasnya. Hal kedua menyangkut ketiadaan wacana pembanding yang menunjukkan keberpihakannya kepada keadilan dalam perspektif demokrasi. Sementara itu, hal ketiga menyangkut harapan pemberdayaan demokrasi untuk melangsungkan hak-hak hidup yang sama. Harapan yang dimaksud berhubungan dengan pemahaman Salmun untuk memberi penekanan atas arti penting kemuliaan dan kehinaan yang sama-sama berpeluang ditempati, baik oleh kelas ménak maupun santana atau cacah, juga pihak kolonial.

$G N$ telah secara produktif mengarahkan berbagai harapan Salmun. Melalui GN, Salmun menunjukkan bermacam reaksi, baik bersifat sebatas konfirmasi maupun sampai ke bentuk penginterogasian, ataupun intimidasi yang dilakukan tokoh santana sebagai representasi kaum pribumi kelas bawah terhadap kaum ménak dan Indo-Belanda. Bentukbentuk konfirmasi, interogasi, dan intimidasi secara dominan diadopsi Nyi Rapiah sebagai tokoh perempuan dari cara-cara bersikap kolonial menyangkut tuntutan keadilan atas persamaan hak sosial, dan sebagainya.

Dengan demikian, wacana mimikri ditunjukkan melalui upaya penguasaan perempuan santana atas otoritas ménak melalui praktik peniruan sebagai olok-olok atas arogansi ménak. Perempuan santana bermimikri juga berdasarkan berbagai cara dan sikap ménak dalam mengintimidasi kaum santana dan cacah. Upaya mengakses kehidupan "Barat" dilakukan perempuan santana dengan jalan: (1) penyesuaian nilai Timur terhadap Barat; (2) hasrat menembus area ménak dan kolonial melalui penyesuaian hasrat berkeadilan yang pada akhirnya beralih kepada hasrat menguasai; dan (3) adaptasi perilaku sebagai pribumi terhadap budaya kolonial, termasuk upaya peniruan atas perjuangan wanita Barat dalam memperoleh hak yang sama.

\section{SIMPULAN}

Cara narasi melaksanakan pembentukan suatu identitas kelas, pembentukan seorang laki-laki ménak, laki-laki kalangan santana, serta perempuan kalangan santana, dihimpun 
dalam $G N$ ke dalam perspektif kaum santana yang bertindak sebagai subjek otoritas naratif. Pertarungan antara kebebasan naluriah dan upaya penindasan dalam $G N$ mengarahkan adanya fakta ambivalensi yang dihadapi kaum pribumi, khususnya perempuan santana dalam menerima moderitas yang dibawa kaum kolonial sekaligus berupaya melemahkan otoritas kaum kolonial; menolak sekaligus menggunakan pelabelan negatif dan stereotipe yang dibawa dari budaya feodal terhadap perempuan untuk melawan tanpa pengekangan terhadap kesewenangan ménak. Sejumlah kondisi di dalamnya tidak ditunjukan untuk mendapatkan kompromi atau transformasi, melainkan sebagai penyeimbang atas berbagai kekurangan menyangkut representasi kelas sosial.

GN memiliki dua kekuatan interpelatif yang diberikan kepada pembacanya. Pertama, novel ini membentuk kaum santana dan cacah sebagai ancaman terhadap rasa penguasaan yang dimiliki oleh para pembaca feodal dan pihak kolonial. Kedua, alam perkotaan dimunculkan sebagai subjek yang mendorong untuk membangkitkan "ancaman" bagi dimensi-dimensi feodal, meski oleh feodal sendiri, terutama yang berjuang pada wilayahwilayah seperti itu.

Penekanan $G N$ pada bentuk-bentuk kekuatan pemberontakan atas perbedaan kelas sosial dihasilkan oleh pengetahuan serta keyakinan atas norma-norma yang dipahami Salmun. Pada sepanjang narasi $G N$, berbagai aspek, tokoh, alur, narator, dan hal lain yang ditandai, bekerja untuk memperkuat tendensi-tendensi sosial di dalamnya. Berbagai tendensi yang dimaksud dieksplorasi melalui keterkekangan, pemberontakan, ancaman, kelabilan, dan peniruan.

Di dalam $G N$, perempuan dipahami untuk menyangkal dan menggugat kaum ménak dengan memberdayakan kemampuan bermimikri terhadap budaya kolonial. Di dalamnya ditunjukkan kemampuan seorang perempuan dalam meruntuhkan penindasan kaum ménak sekaligus menggangu otoritas utama, yaitu kolonial.

\section{DAFTAR PUSTAKA}

Bhabha, H. K. (2004). The Location of Culture. London and New York: Routledge Classics. Drayton, R. (2019). Race, Culture, and Class European Hegemony and Global Class Formation, Circa 1800-1950. Cristof Dejung, David Motadel, Jurgen Osterhammel (Ed.), The Global Bourgeoisie :The Rise of the Middle Classes in the Age of Empire (pp. 339-358). Princeton University Press. https://doi.org/10.1515/9780691189918-019

Gouda, F. (2007). Dutch Culture Overseas: Praktik Kolonial di Hindia Belanda 1900-1942 (Cet. ke-2). Terjemahan Jugiarie Soegiarto \& Suma Riella Rusdiarti. Jakarta: Serambi. Hellwiq, T. (2001). Asian Women in The Lives of Dutch Tea Planters: Two Narratives from West Java. Indonesia and the Malay World, 29:85, 161-179. 
https://doi.org/10.1080/13639810120102049

Loomba, A. (2003). Kolonialisme/ pascakolonialisme. Yogyakarta: Bentang Budaya.

Lubis, N. H. (1998). Kehidupan Kaum Ménak Priangan 1800-1942 (Cet. ke-1). Bandung: Pusat Informasi Kebudayaan Sunda.

Meer, A. H. C. van der. (2014). Ambivalent Hegemony: Culture and Power in Colonial Java, 1808-1927. Disertasi. New Brunswick, New Jersey: The State University of New Jersey. Murwani, C. D. T. (2013). Representasi Perlawanan Pribumi Masa Peralihan Abad Ke-19 Sampai Ke-20 di Hindia Belanda dalam Novel De Stille Kracht (Karya Louis Couperus) dan Bumi Manusia (Karya Pramoedya Ananta Toer). Disertasi. Yogyakarta: Universitas Gadjah Mada.

Rosidi, A. (2002). Beber Layar (Cet. ke-3). Bandung: Kiblat.

Said, E. W. (2017). Kekuasaan, Politik, dan Kebudayaan (G. Viswanathan (ed.); Cet. ke-1). Penerjemah: Hartono Hadikusuma \& E. Setiyawati Alkhatab. Yogyakarta: Narasi.

Salmun, M. A. (1966). Gogoda ka nu Ngarora (Cet. ke-2). Bandung-Jakarta: Pusaka Sunda \& Balai Pustaka. 